\title{
TEMPORAL RELATIONS IN AFFECTIVE HEALTH
}

\author{
Elsa Kosmack Vaara, Mobile life centre \\ Iuliana Silvăşan, Technical University of Cluj Napoca, Romania. iuliana.silvasan@aut.utcluj.ro \\ Anna Ståhl, Mobile life centre \\ Kristina Höök, Mobile life centre
}

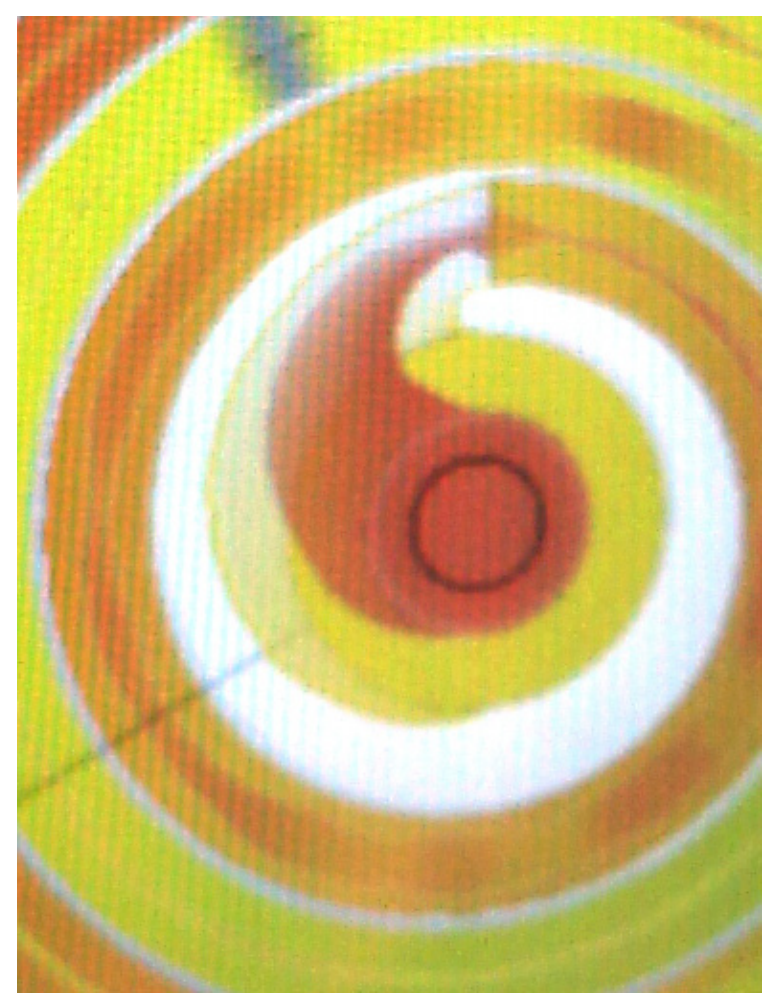

Close up picture from the latest Affective Health interface, the "spiral".

>>> Please press to watch Affective Health videos

\section{ABSTRACT}

In the Affective Health project we explore possibilities of how to, through biofeedback support users in making sense of the relationship between their stress and their behavior in everyday life. Affective Health is a tool for visualizing patterns and trends of bodily and contextual information. It is particularly important that the design reflects changes over time as this is how people start recognizing patterns in their own behavior and connect it to their bodily reactions. We spent substantial effort sketching and testing ways of portraying time that would move us away from more mathematically inspired representations such as for example graphs and calendars. Instead, we want users to see the signals our bodies emit as part of themselves, of their own ways of being in the world, alive, acting and reacting to their environment. We have explored many possible, alternative ways of visualizing temporal representations through biofeedback. For example as the relation between different places and with time as different layers of history in a concept inspired from ecology. The latest and most developed concept is a cyclic repetition of biodata mapped on a spiral shape.

\section{INTRODUCTION}

In the Affective Health project we have designed a mobile service that empowers people to monitor and understand their own stress levels vis-à-vis their everyday activities. The current system logs a mixture of biosensordata and other contextually oriented data and transforms these to colorful, animated expressions on a mobile phone. It is particularly important that the design reflects changes over time as this is how people start recognizing patterns and characteristics in their own behavior and connect it to their bodily reactions. The representation of time has therefore been crucial during the development of the system. Temporal relations such as duration, rhythm and pace provides us a form for structuring our living and experiences[16]. But every individual, perceives the world and changes in it differently depending on his/her prior experiences. Can we express temporal relations in way that touches upon and relates to every person's own subjective experience? During our design process we have learnt that there are possibilities to escape the standardized ways of representing temporal events and changes. Instead, we design visualizations and representations that tell us more than the ordinary illustrations of time in the way it links temporal representation with our behavior through biofeedback data. In this paper we will present our efforts in sketching and testing ways of portraying time as a medium for biofeedback data. 


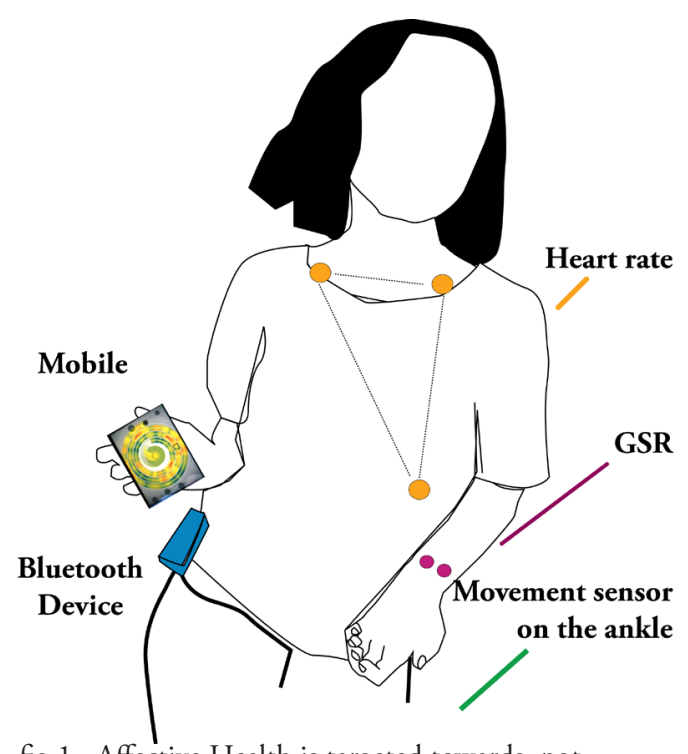

fig 1. Affective Health is targeted towards, not the everyday scribbler that creates her own private expression and thoughts, but to users who want to see themselves and their bodily reactions from a different perspective, mainly to reflect on stress related issues in their lives.

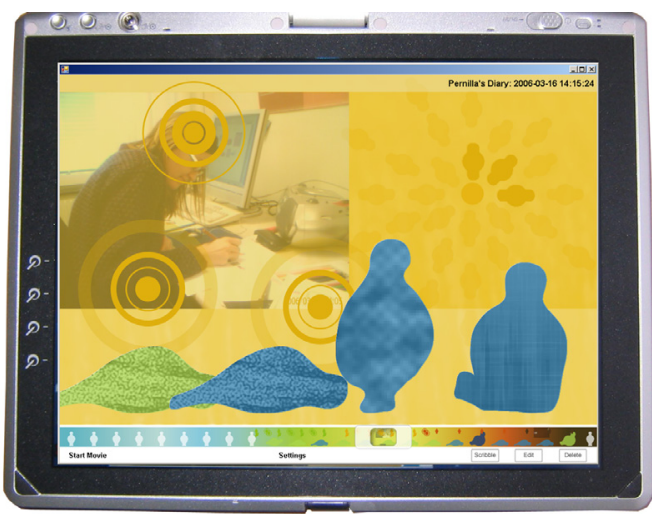

fig 2. By inspiration from the Affective Diary, users reflected upon their lives: "Now I know that it is $O K$ that this is this kind of trigger that will trigger me and then I can think about that before and then I can kind of become more aware of my own states. Even though I am pretty aware already it becomes so obvious when you see it like this, I think."

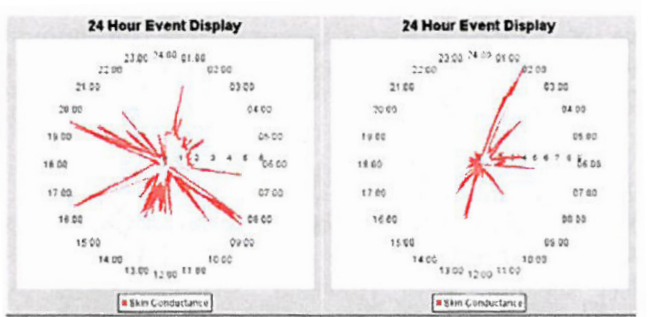

fig 3. The" iCalm" project expands the general clock-like representation by adding 24 hours to the view. The representation shows GSR measurements as the arms of a clock, their length indicating the values recorded from the sensors.

This visualization limited in fluency as it does not allow any possibility to fluently scroll through the data over time, but one needs to view separate clocks for different days.

\section{BACKGROUND}

The Affective Diary [20] [fig.2] was the first project in our journey exploring biofeedback as a process of embodied enquiry. There, the idea that the various social, physical and cultural factors that contribute to an experience have to be expressed as a whole, laid the ground for the interactive art based expression chosen for the interface. The Affective Diary was an attempt to make use of a range of design qualities for transforming individual understandings and experiences into an interactive media: Familiarity: The design is abstract enough to trigger the users fantasy, but still displaying information in such a way that users recognize themselves and events in their lives. Openness to personal expressivity: By using open-ended expressions and let them add notes and arrange data, users could create their own interpretations and express themselves and their thoughts. Awareness of contradictions between modalities: There are multiple kinds of modalities to use in a design process: It is important that design modalities like colors, shapes, animations, gestures, sound and so on harmonize and strengthen one-another rather than being contradictory. If a contradiction is used, it should be made with purpose with the aim of, for example, creating subtle or dynamic expressions mirroring how emotion processes can be subtle, complex, and combined [21].

\section{AFFECTIVE HEALTH SYSTEM}

While Affective Diary was a tool to keep a regular record of daily events and experiences, which also recorded bodily memorabilia [21] [fig.2], Affective Health aimed to work in realtime, on your mobile phone, involving users in both a biofeedback and a reflective loop [7]. The Affective Diary system turned out to be a successful system in terms of allowing users to make their own interpretations of the events in their life. We therefore decided to continue to make use of the same design qualities when we moved on and designed Affective Health. In Affective Health we designed a tool to reflect lifestyle and stress, which automatically collects bio data and presents it in real time, without making diagnoses or providing the user with warnings or advice [19]. With the increased interest in our own health and the acknowledged problem in the western society that long-term stress leads to chronic illnesses such as cardiovascular problems, a new kind of reflection tools have arisen on the market, for example the "pip" (personal input pod) by Vyro games [22] or the "Icalm" [fig.3] [16]. Some of these products diagnose stress, and make use of warnings and messages for the user as a result of inferences on the biofeedback data. Making decisions for the user might interfere with her action of reflecting upon herself and becoming aware of her behavior and reactions in life. An early study using two concepts of Affective Health interfaces in a Wizard-of-Oz study [5] helped us to better formulate the specific requirements on experiential design qualities; By using an interface with openness and ambiguity, the user gets more involved with the system through attempts of understanding and interpreting the meaning in the data. The system should open up to selfreflection for the user, which can be created with an interactive history of the prior states [fig 6]. To have an active interface that is pleasant to interact with, it is important that discrete states are avoided and that the data is visualized in a fluent way. The aliveness of the system is important in the immediate experience of interacting and identifying with the system. For example the user should perceive the visualization and the interaction to have a strong connection between action and outcome to get involved and find the system 

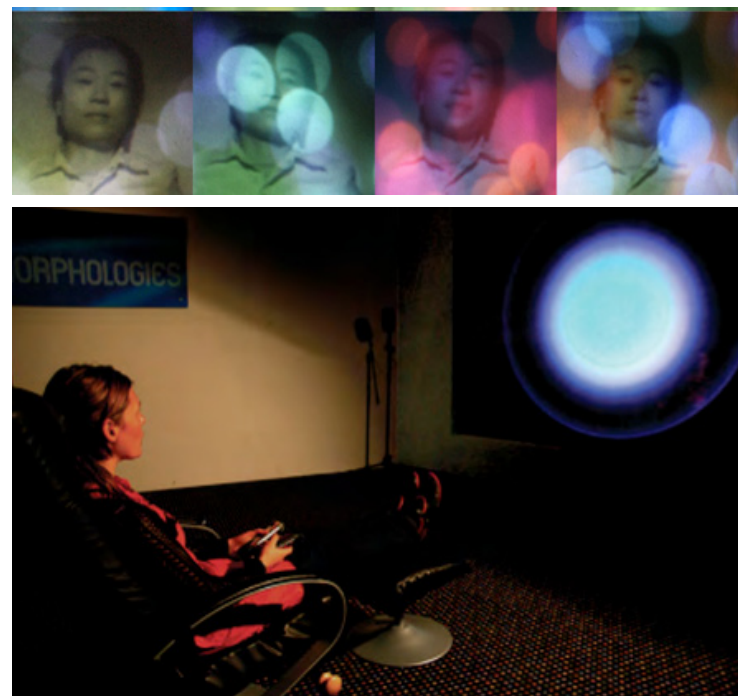

fig 4. In George Khut's interactive artwork visitors are invited to sit down and see their heartbeats or skin conductance measurements mirrored back to them in colorful, suggestive, organic shapes. "Many people lack the ability to concentrate for any extended period of time on the nuances of their own physicality, thus audio-visual biofeedback provides a means by which they can enter into sustained engagement with these behaviors and sensations." George Poonkhin Khut 2006

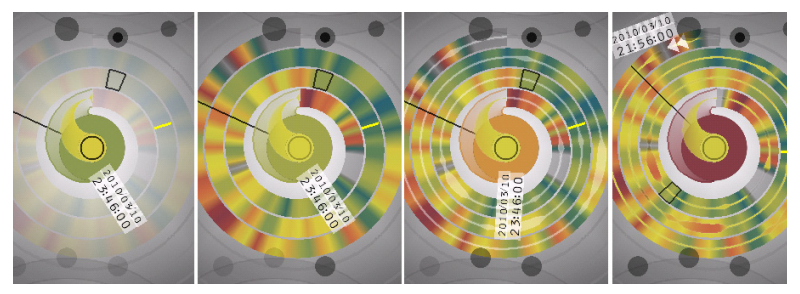

fig 5. Left: Real time data is visualized in the centre of the spiral: The black ring is pulsating as the heart rate and the colour inside it also shows the heart rate. The color inside the larger circle expresses the arousal. Second left: Arousal is shown by the colours of the background in the spiral ribbon. Third left: A shape inside the spiral ribbon changes thickness depending on movement. Right: The area inside the movement shape changes colours with the heart rate.
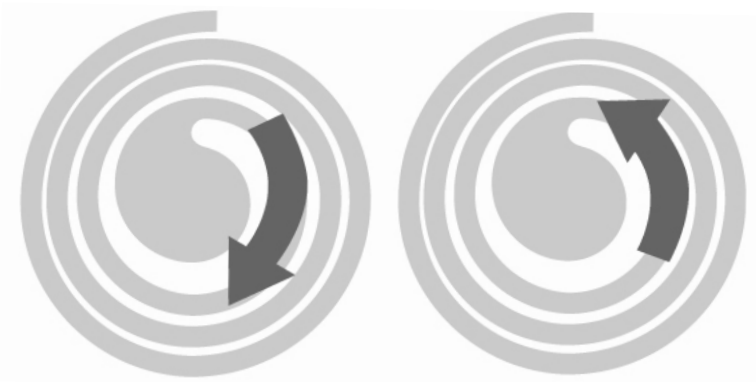

fig 6. Left: The biofeedback data grows outwards from the center into the spiral creating the history. Right: The user can spin the spiral ribbon in any direction. To move to past data the spiral ribbon is spun towards the center. The ribbons are more stretched further out in the spiral to create a parallel cyclic repetition of biofeedback data. This supports the comparison of cyclic happenings [6] and supports the interaction with the history of the prior states. aesthetically pleasing. An inspiration to both our design and our thinking has been the affective interactive stance [ $3 \& 8$ ]. Their perspective is that emotion should be portrayed interactively, as processes, unfolding over time, where the interpretative and reflective powers remain in the hands of the users, not the system [19]. Another source of inspiration is from media and art. G. Khut's work in interactive body-centered art is an example showing the use of biosensors in interactive artwork [15] [fig.4]. The Affective Health system provides data about everyday life in real life settings. It is impossible to reliably diagnose our reactions in real life, where we are involved in all sorts of activities that engages us at different emotional levels. Reactions are different depending on the individual and the sensors reliability can change depending on the environment.

\section{TECHNICAL BASIS FOR THE SYSTEM}

The Affective Health application translates biodata from sensors, worn by the user on an everyday basis, into an interactive interface [fig.1]. Data from the sensors is transmitted to the mobile phone using Bluetooth. We use Galvanic Skin Response (GSR), movement and heart rate sensors. The GSR sensors measure changes in the electrodermal activity which is characterized by perspiration, a basic manifestation of short term stress. To measure heart rate we use electrocardiogram (ECG) sensors attached to the user's chest. But, the body may respond with increased perspiration and heart rate for many reasons, not only because of stress, but, for example, from energetic physical movement. We therefore also measure users' movement using a tri-axial accelerometer.

\section{VISUALIZING}

\section{subjective, abstract time through biofeedback}

Because for the current application visualizing the concept of time is crucial, we will start out by discussing some issues in relation to that. "Time is intangible, but ubiquitous in our experiential world and yet nowhere to be found in the physical one"[13]. To perceive time, we don't have any specific organ. All our sensory modalities are possible entries at the interface of physical time with perceptual time. For example our experience of time depend upon the many factors that mediate time e.g. attention, memory, arousal and emotional states [22]. People often assume that an intense activity is more likely to be important and therefore remembered [24]. Based on this assumption, situations could be illustrated differently, i.e. contracting periods in which there are no significant fluctuations in the signal recorded from the sensors and expanding those that suggest an intense activity. This idea is tempting, offering an alternative for subjective time, but may lead to errors in our perception of time and creation of reality. From a wellbeing and life style evaluation point of view it is important to be aware of the non-intense periods as well, not contribute to their natural fading behavior, but be aware of them and the pattern they contribute to. For example, in recent studies with the latest Affective Health interface, the "Spiral" concept, the users reflected upon "green" moments, where they acknowledged that sometimes they were more calm than they actually thought themselves, which was a calming feedback possibly leading to a better everyday feeling. We could confirm from these 

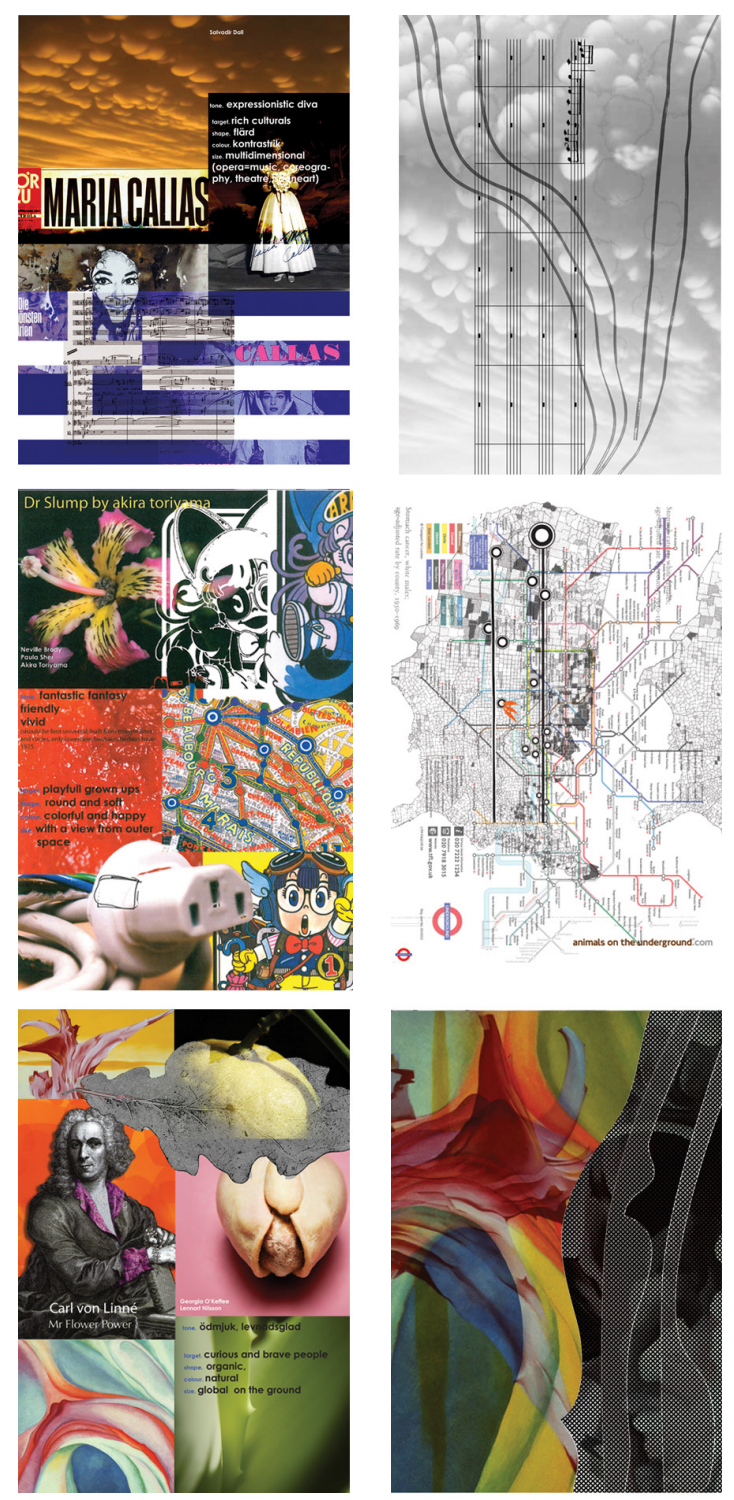

Fig 7. In the "Hall of Fame" method we chose characters to build inspirational material upon (left row): Carl von Linné, Maria Callas, Manga figure Dr Slump. From these characters we get ideas of expressions tied to: tone (e.g. sad, aggressive), target (e.g. playful, unemployed, brave), shape (e.g. geometric, soft), colour and size (e.g. green, global, multidimensional, ). Second phase (right row) is an abstraction of the hall of fame moodboards into a more interface-looking concept board.

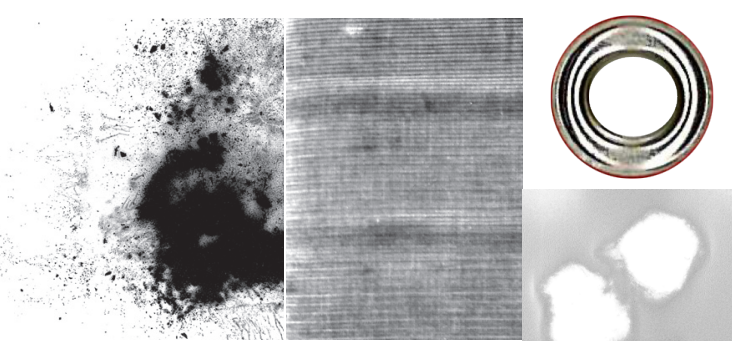

fig 8. Scanned material for creating digital material: In designing for time, we experiment with digital art to create prototypes for visualizations. Designing is not only to make the system work smoothly and being reliable, or making a pretty interface, but to search for aesthetics that can contribute to a more motivating relationship between the user and the application. [4]. reactions that it was as important to discover moments of rest as reflecting upon a stressful day at the office [6].

\section{Abstract time}

The metaphysical nature of time makes it hard to grasp. First of all time is not really what we experience, but changes and events in time [11]. Time would by this understanding be about duration and intervals. But how can temporal relations be visualized as for example long or short? You cannot point your finger at a "duration object" as you can at a house or a sound source, still time can be experienced when you wait for something to happen or to end. It can also be experienced in more subtle ways when you perform or listen to music. In music, bars, beats and notes are abstracting the duration of time while tempo and acceleration are the time derivatives [12]. StAugustine's answer to how to measure time in Confessions of St Augustine, is that what we are measuring, when we measure the duration of an event or interval of time, is in our memory. It is some means of our memory of the event (perhaps particularly our memory of the beginning and end of the event) that allows us to form a belief about its duration. The abstraction is a mechanism that helps the mind grasp and organize the amount of information it receives. It makes use of common knowledge, learned notions about time and life in general, but personalizes the process in a manner that helps users understand and identify with the information. Current implementations in the project Affective Health are built upon the concept of memory, remembering and reflecting on past events and behaviors by identifying patterns of biofeedback data over time.

\section{DESIGN EXPLORATION}

When exploring the design space of how to represent biofeedback data over time we focused on identifying questions to continue researching this theme, not to create a final solution [26]. We performed a process of investigating and thinking through aesthetic reasoning [1] where we used our skills as designers to develop visual abstractions in a playful way. In the start we built a graphic library through the "hall of fame" creative method [fig.7]. Then materials like cloth, earth, flowers and stones were scanned and processed to be used as digital art in the sketching and as textures in the prototype implementation [fig.8].

\section{Examples of Affective Health temporal interfaces}

The basic framework qualities from the Affective diary project and the design qualities fluency, aliveness and possibility for comparison were the preconditions for the Affective Health project: Within these constraints we started exploring representations of time. Let us describe a selection of the sketches and concepts from the process of designing for temporal relations.

Representing the connection between moments in time as a relation between places is an interesting exercise to escape the past-present-future idea. In the Geo concept [fig.10] the user is forced to watch herself from a geographical perspective. How much time do I spend at, for example work, home, the gym or outside, and how does the biofeedback change? (e.g. Do I get more relaxed at work if I spend more time in the gym?) Each square represents a place chosen by the individual. This concept started an important discussion about our way of abstracting time: In our culture we tend to reduce time into standardized units (seconds, minutes, hours and so on) in the same way we give objects their spatial relations [14]. We saw that there are possibilities to move 


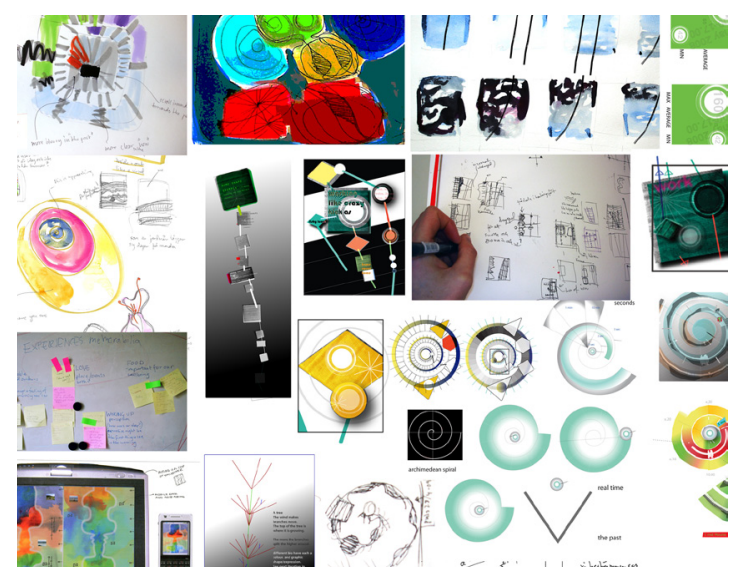

fig 9. Collage of sketches from the playful sketch process.
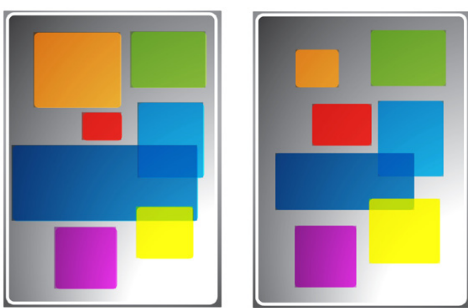

fig 10. In the Geo concept the places are separated by colour. Only arousal is represented as biofeedback visualized by the shape of the rectangles: The more horizontal shape, the lower arousal. There is no time line, only the temporal relation between the rectangles: the bigger rectangle, the more time you spent there.
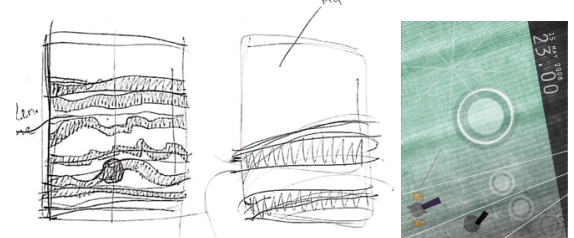

fig 11. Layer interface sketches

fig 12. Layer interface prototype.

The heart rate is visualized by $\mathrm{a}$.. circular shape pulsating with the heartbeats.

The whirl represents movement $•$ and the colour arousal.

\section{fig 13. The user's most} recent state is shown at $\cdot$. leftmost top. Past data build layers of historical data in the bottom of the. screen.

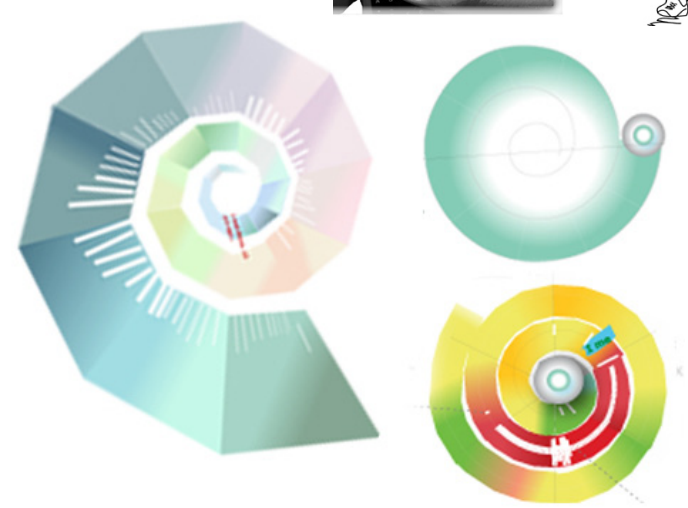

fig 14. Starting with sketches inspired by a natural shell with all the beauty and asymmetry it contains, we then decided to use the Archimedes spiral (right) because it moves away from the origin at a constant rate and therefore is more compact [9]. away from these mathematically inspired ways of representing temporal events and changes and link representations of time to other qualities, for example geographical places. This sketch was not taken further because we feared that it would be impossible to create a fluent and alive expression over time with the separated squares. The user would not be able to recognise her own living, pulsating experience in the interface since the changes in it would be very slow.

Two of our interfaces have been fully implemented and tested with real sensors and Bluetooth transmission. First the Layer concept [fig. 11,12,13] and later on the Spiral concept[16]. In the Layer concept the flow of time is visualized as biofeedback data "falling" downwards building layers of history at the bottom of the screen [10]. When looking back in time the user would reveal historical layers by dragging them up again [13]. The spiral concept [5] represents the biofeedback data as colors and shapes mapped on a spiral. The visualizations of the biosensor data in both the implemented interfaces improve the aliveness through using a pulsating movement to connect to the well known concepts of the rhythm of a heart, but also by moving the data in time. Real-time information from the biosensors are visualized with a live blend of colors and animated shapes in both the interfaces. Although in the Layer interface there were some fluency problems: Prior states, were summarized into static descriptions representing one minute of activity each. This created a disjoint experience between past and present. Users reactions on this concept were for example: "I don't want to have to wake the system up to see. I want to feel that I am a part of a happening, not only right now" "what made me be here and be like this" We understood that the user felt expressed by, and familiar with, the visualization, but the overall understanding of yourself as a whole over time was lacking.

The fluency was improved in the spiral interface where the visualizations have fluently blended states in both colours, shapes and animations that continuously grows outwards from the center into the spiral creating the history [6, 15]. In this concept the combination of the qualities of fluency and aliveness bring our system close to what Löwgren describes as pliability [26]: An interactive visualization that feels involving, malleable, with a tight connection between action and outcome which encourages exploration. To create the repetetive cyclic effect in the spiral interface where users can see three parallel cycles at a time we had to let data on the outer bigger cycles cover a longer spiral area [fig.15]. One user was puzzled by the stretched illustrations of the past in comparison to the most recent data from the inner circle of the spiral, while others appreciated the possibility of comparing parallell events, for example three energetic family mornings.

In the tests of the Spiral concept some users reflected upon their behavior in interaction with others. They noticed changes in the colours and animations of the interface as a result of their emotional reactions. These changes are an indicator of variations both in the rhythm of time and in the rhytm of the biofeedback data. When we socialize with other people we adjust our way of being to match the other person's rhythm and pace [22]. This informed us that we could have designed more for social temporality. Users also expressed the need for a future [2]: "one has to have some time left to live too". Time does not stop at the present as it might seem like in the Spiral and Layer visualizations where there is no representations of empty, unwritten future. Maybe we cannot foresee all our reactions in everyday life but we should take into account the strong force of expectation and belief that we have as human beings. 
10 seconds in three parallel cycles

Fig 15. To create the repetetive cyclic effect, where users can see three parallel cycles at a time we had to let data on the outer bigger cycles cover a longer spiral area
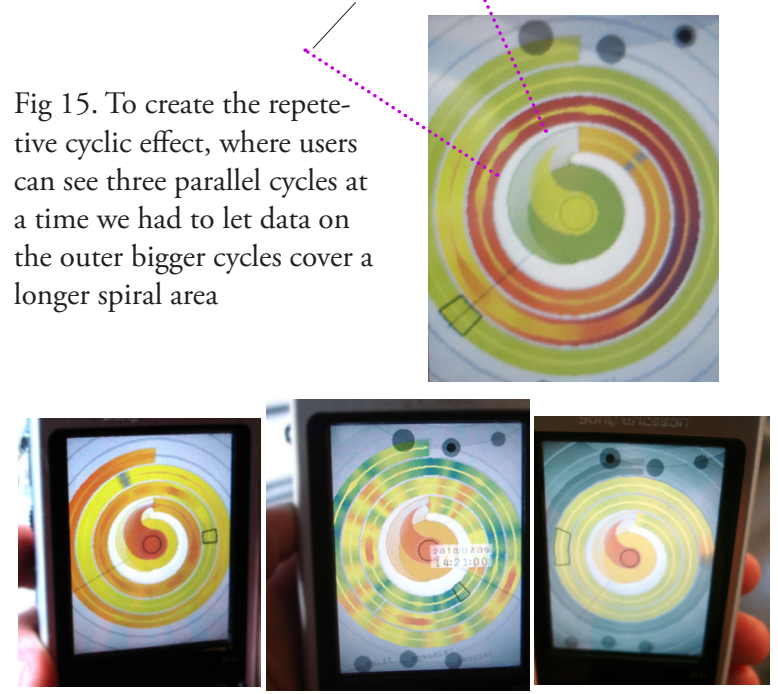

Fig 16. The spiral shows the data in in different compressions. As the spiral ribbon represents historical data each revolution symbolizes a standard time unit, meaning that a revolution can either represent one minute of data,( left) one hour (middle) of data or one day (right) of data depending on which one of the three views is used.

\section{DISCUSSION}

Our attention, memory, emotional states and other people constantly have impact on our experience of time. Therefore, the visualization of temporal relations in Affective Health is interesting from more than one point of view: The sensor data brings awareness to the user about her emotional reactions in life that she might not always be aware of. It also expresses temporality in her life by turning the biofeedback into visual patterns that can be interpreted into rhythm, pace and memories. Time is one of the most powerful influences on our thoughts, feelings, and actions, yet we are usually totally unaware of the affect of time in our lives. Temporal visualizations could offer people ways to look upon their lives from a new perspective. We can conceptualize the experience and perception of time and design for it in the way we design for spatial distances and other relations between objects. Although we should use modalities and measurements specific for temporal relations, for example rhythm, pace and memory.

While we have explored many possible, alternative, ways of seeing bodily data visualized and mirrored back to users in novel temporal representations, there are some aspects that we have not been able to capture: social aspects of time and possibly, a way of seeing the future. We would like to go on investigating how the metaphysical nature of time, instead of being a rigid framework that forces everyone to fit in can be something that enhances our subjective and embodied being in the world!

\section{References}

[1] Akner-Koler Cheryl, Form and Formlessness, Axl Books 2007, ISBN 97891-976644-6-2

[2] André C, Unpublished Master thesis

[3] Boehner, K., DePaula, R., Dourish, P., and Sengers P. Affect: From Information to Interaction. Critical computing Conf, Århus, Denm, 2005.

[4] Bolter Jay David, Gromala Diane, Tranparency and Reflectivity: Digital Art and the Aesthetics if Interface Design, MIT Press 2004

[5] Ferreira, P., Sanches, P., Höök, K. Jaensson, T. License to Chill! How to empower users to cope with stress. NordiCHI, pp. 123-132, ACM Press, Lund, Sweden, 2008.

[6] Hernegren F, Unpublished Master thesis

[7] Höök, K. Affective Loop Experiences - What Are They? Persuasive 2008, H OinasKukkuonen et al. (eds.), LNCS 5033, pp. 1 - 12, Springer Verlag (invited keynote)

[8] Höök, K., Ståhl, A., Sundström, P., and Laaksolahti, J. (2008). Interactional Empowerment. CHI2008, pp. 647-656, Florence, Italy,

[9] John V. Carlis and Joseph A. Konstan, Interactive Visualization of Serial Periodic Data, San Francisco Nov 1998, UIST'98.

[10] Kosmack Vaara, E., Höök, K., and Tholander, J. Mirroring bodily experiences over time. Work in progress at CHI 2009. Boston, USA

[11] Le Poidevin, The Images of Time: An Essay on Temporal Representation (Oxford: Oxford University Press, 2007)

[12] Lee Eric Designing time-based interactions with multimedia, ACM international conference on Multimedia, Singapore, 2005, pp. 1037-1038 (doct symp)

[13] Marc Wittmann and Virginie van Wassenhove, The experience of time: neural mechanisms and the interplay of emotion, cognition and embodiment, Phil. Trans. R. Soc. B 2009 364, 1809-1813 doi: 10.1098/rstb.2009.0025

[14] Mazé Ramia, Occupying time, Design technology, and the form of interaction. Axl Books, Stockholm 2007, ISBN 978-91-976644-1-7
[15] Poonkhin Khut G. Development and Evaluation of ParticipantCentred Biofeedback Artworks, Doctorate of Creative Arts 2006

[16] R. Fletcher, K. Dobson, M.S. Goodwin, H. Eydgahi, O. WilderSmith, D Fernholz, Y. Kuboyama, E. Hedman, M.Z. Poh and R.W. Picard, "iCalm: Wearable Sensor and Network Archintecture for Wirelessly Communicating and Logging Autonomic Activity", IEEE Transactions on Information Technology in Biomedicine, USA, 2009, pp. 215-223

[17] Rosengren C, Tiden som form och upplevelse - om relationen mellan arbete och tid, arbetsliv i omvandling | 2006:3, isbn 91-7045-784-0 | issn 1404-8426

[18] Sanches.P, Höök.K, Vaara.E, Weymann.C, Bylund.M, Ferreira.P, Peira.N, Sjölinder.M. Mind the Body! Designing a Mobile Stress Management Application Encouraging Personal Reflection, DIS 2010, Aarhus, Denmark

[19] Sanches, P, Vaara, E, Sjölinder, M, Weymann, C and Höök, K. Affective Health - designing for empowerment rather than stress diagnosis. Workshop, Know thyself: monitoring and reflecting on facets of one's life, CHI 2010, Atlanta.

[20] Ståhl, A., Höök, K., Svensson, M., Taylor, A. and Combetto, M. Experiencing the Affective Diary. JPUC: Vol 13, Issue5 (2009), P. 365.

[21] Ståhl, A., and Höök, K. Reflecting on the Design Process of the Affective Diary. NordiCHI 2008, Oct 20-22, Lund, Sweden

[22] Sylvie Droit-Volet and Sandrine Gil, The time-emotion paradox, Phil. Trans. R. Soc. B 2009 364, 1943-1953 doi: 10.1098/rstb.2009.0013

[23] Vyro games "http://www.vyro-games.com/products/PIP/PIPMain.php" [24] William James, The Principles of Psychology, (1890)

[25] Zimmerman J, Forlizzi J, Evenson S, Research Through Design as a Method for Interaction Design Research in HCI, HCI Institute and The School of Design Carnegie Mellon University, (CHI 2007)

[26] Thoughtful interaction design, Jonas Löwgren and Erik Stolterman, 2004 MIT Press 